\title{
Trail erosion in the area of the Seven Rila Lakes Cirque, Rila National Park, Bulgaria
}

\section{Ерозия на пътеките в района на циркуса на Седемте рилски езера, Национален парк „Рила“, България}

\section{Radenka Mitova \\ Раденка Митова}

Sofia University “St. Kliment Ohridski”, 15 Tsar Osvoboditel Blvd, 1504 Sofia, Bulgaria; E-mail: r_mitova@gea.uni-sofia.bg

\begin{abstract}
The study is of a pilot nature and aims to investigate and document the trail erosion in the Seven Rila Lakes Cirque, Rila National Park, Bulgaria. The width and maximum depth of the trails were measured in 31 randomly selected points on the trail network. The results show that in half of the studied cases there is a trail degradation, but in other cases, recovery processes are observed.
\end{abstract}

Keywords: trail degradation, erosion, recreation ecology, geoheritage, Seven Rila Lakes.

Туристическите пътеки концентрират посетителския поток, осигуряват достъп до забележителностите и стоят в основата на качественото рекреационно преживяване (Leung, Marion, 1996; Marion, Leung, 2001) Проблемите с деградацията на пътеките се свързват преди всичко с ефектите на разширяване и врязване на пътеките, както и загуба на почвената покривка. Изследванията на такава тематика са в полето на рекреационната екология и целят да предоставят информация за това как да се предпазят пътеките от деградиране. Въпреки че екологичните последици от пътечната деградация могат да бъдат значителни и необратими, съществуват ефективни управленски интервенции, чрез които пътеките могат да станат по-устойчиви и да се минимизират негативните въздействия (Leung, Marion, 1996, 2000; Marion et al., 2016).

Проблемът е особено остьр в случая с атрактивния каскаден циркус на Седемте рилски езера (ЦСРЕ) на територията на НП „Рила“, още повече, че според някои автори (Sinnyovsky, 2014, 2015; Tsvetkova, Sinnyovsky, 2015) ЦСРЕ трябва да се разглежда като обект на нашето геонаследство. Неблагоприятните екологични последици върху езерата от посетителския поток са тема на широка дискусия и безпокойство през последните години и особено след построяването на въжена линия през 2009 г. Обикновено се приема, че увеличеният посетителски поток причинява еутрофикация на езерата, поради увеличената ерозия на пътеките. В научната литература са повдигнати множество опасения и предупреждения (Velchev et al., 2011; Nikolova et al., 2012; Nedkov et al., 2014), но целенасочени изследвания за установяване на щетите до момента не са предприемани. Целта на това проучване е да се изследва и документира деградацията на пътеките в района на ЦСРЕ.

В периода 15-17.09.2020 г. е извършено измерване на ширината и максималната дълбочина на пътеките в 31 предварително определени точки по пътечната мрежа в ЦСРЕ. Изследването е ex-post, съобразено с преминаването на пика на посещаемостта в ЦСРЕ. Подборьт на точките е случаен и е извършен в ГИС среда (QGIS 3.14) въ3 основа на предварителна векторизация на всички пътеки в района на водосборната област на ЦСРЕ, която е направена на базата на Дигиталната ортофото карта (M3X, 2013). Навигацията на терен до избраните точки е осыществена с помощта на мобилното прило- 
жение QField. Измерването на ширината и дълбочината на пътеките е извършено съобразно установените стандарти, описани в научната литература (Martin, Butler, 2017; Jewell, Hammitt, 2000; Marion, Leung, 2001; Marion, Olive 2006; Rangel et al., 2019; Salesa, Cerdà, 2020). За анализ на събраните данни е използвано полупроизведението от ширината и максималната дълбочина на пътеките, което е интерпретирано като производен показател за напречно сечение на пътеката, респективно, като индикатор за деградация на пътеките.

Получените резултати показват голяма вариабилност на данните (фиг.1а).

Регистрираните нулеви стойности за ширина, максимална дълбочина и напречно сечение на пътеките се отнася за кръговите следи, формирани от практикуването на ритуала Паневритмия от членовете на Бялото братство (точки 6 и 24). Следите са ясно различими на ортофото снимката от 2013 г., но към момента на проучването тези пътеки са напълно заличени. Подобни възстановителни процеси се наблюдават и по пътеки, които в миналото са били интензивно използвани, но в последствие са изоставени. Типичен пример се наблюдава в точка 7 (фиг. 1f). Тези резултати показват, че процесите на деградация на пьтеките се характеризират с известна степен на обратимост, а възстановителните процеси протичат в рамките на няколко години.

Ширината на пьтеките на места достига до крайно неприемливи стойности, надхвърлящи $27 \mathrm{~m}$ (фиг. 1a). Високи стойности на ширина на пътеките се наблюдават предимно на заравнени терени и в голяма част от случаите става въпрос за множество паралелни трасета, които с времето постепенно се сливат. Средната ширина на пътеките също е неприемливо висока, достигаща почти $5 \mathrm{~m}$, а високата стойност на стандартното отклонение говори за повишен риск от неоправдано разширяване на пьтеките. Все пак в близо половината от изследваните точки, пътеките са тесни до умерено широки (до $2,5 \mathrm{~m}$ ) (фиг. 1b). В останалите случаи е необходимо да се вземат мерки за ограничаване на ефекта на утъпкването. Най-сериозен е проблемът по пъ-

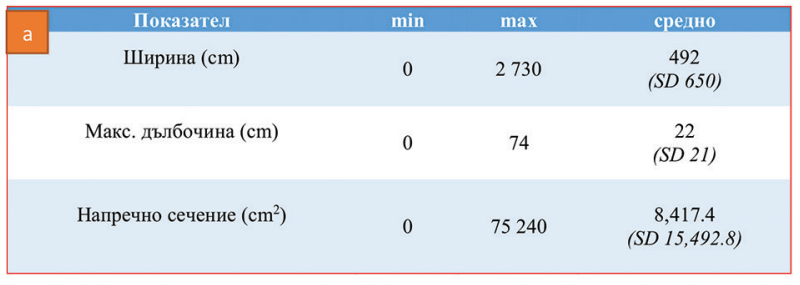
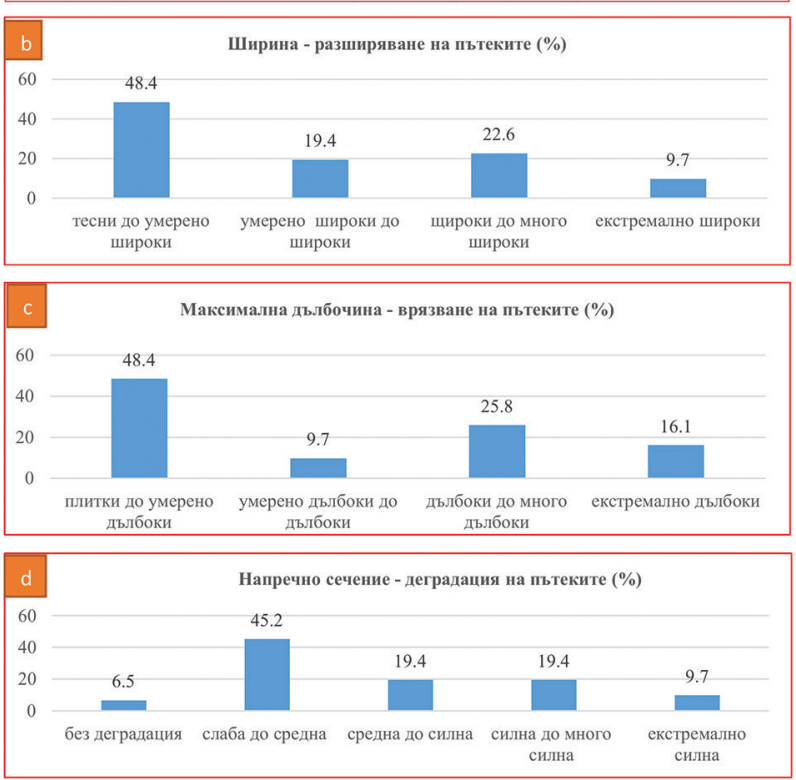

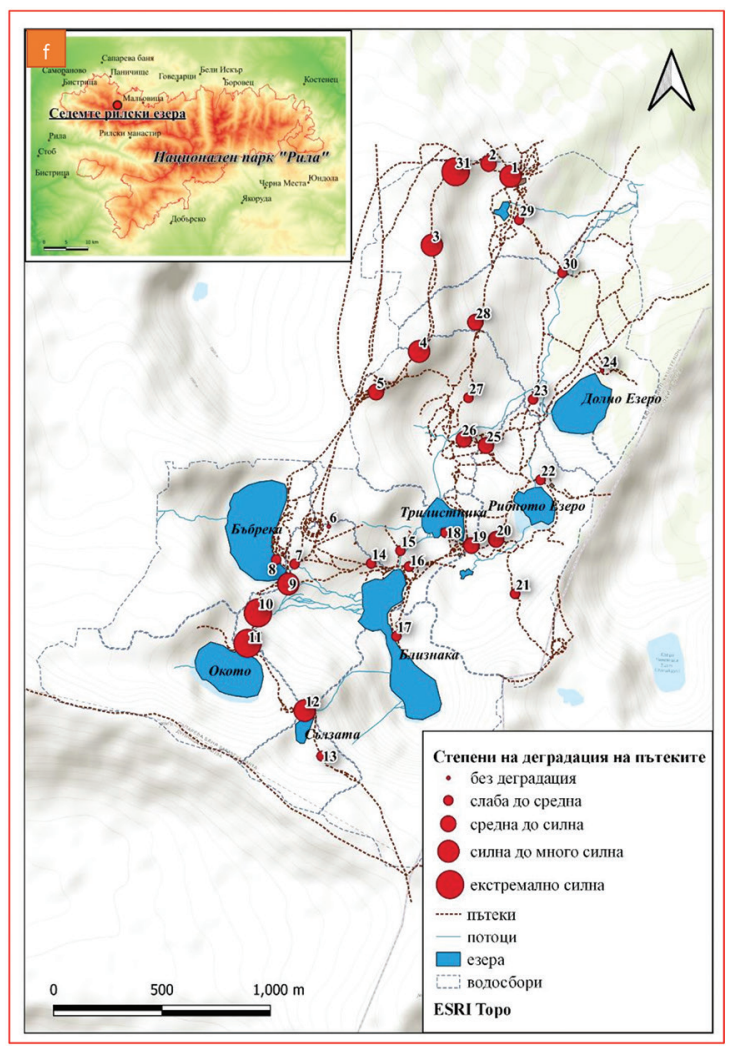

Фиг. 1. Състояние на пътеките в района на Седемте рилски езера: а) параметри на пътеките; b) честотно разпределение в зависимост от оценките за разширяване на пътеките; с) честотно разпределение в зависимост от оценките за врязване на пътеките; d) честотно разпределение в зависимост от оценките за деградация на пътеките; f) локализация и идентификационен номер на точките на измерване; пространствено разпределение на оценките за деградация на пътеките, вкл. спрямо водосборите. 
теката между х. Рилски езера, през Сухия рид към ез. Бъбрека.

Неприемливо високи стойности проучването регистрира на места и за дълбочина на пътеките (фиг. 1a). Дълбоко врязване на пътеките се наблюдава предимно на стръмни терени, а най-високи стойности са регистрирани по пътеката от ез. Бъбрека, през ез. Окото до ез. Сълзата (фиг. 1f). Подходящи управленски мерки в тези случаи са стабилизиране на пътечното покритие и осигуряване на дренажни и противоерозионни съоръжения.

В близо половината от изследваните точки данните показват високи нива на деградация на пътеките (фиг. 1d). Стандартното отклонение на средната стойност на напречното сечение на пътеките също е голямо (фиг. 1a), което може да означава повишен риск от експанзия на проблема. Без съмнение това налага прилагането на активни мерки за намаляването на негативните въздействия на посетителския поток върху природното наследство на Седемте езера. В пространствен аспект обаче данните за деградация на пътеките, отнесени към водосборите на езерата и свързващите ги потоци, не предоставят категорични доказателства за връзка между пътечната ерозия и еутрофикационните процеси (фиг. 1f). В бъдеще се необходими допълнителни и задълбочени проучвания в този аспект.

Събраните данни са добра изходна основа за проследяване на бъдещи промени и могат да послужат като основа за изграждане на мониторингова система на екологичните въздействия на рекреацията в района на ЦСРЕ, както и за вземането на информирани устойчиви управленски решения.

Благодарности: Изследването е финансирано от Национална програма „Млади учени и постдокторанти“ към Министерство на образованието и науката.

\section{Литература References}

Jewell, M., W. Hammitt. 2000. Assessing soil erosion on trails: a comparison of techniques. - In: USDA Forest Service Proceedings RMRS-P, 15, 5, 133-140.

Leung, Y. F., J. Marion. 1996. Trail degradation as influenced by environmental factors: A state-of-knowledge review. J. Soil Water Conserv., 51, 2, 130-136.
Leung, Y. F., J. Marion. 2000. Recreation impacts and management in wilderness: A state-of-knowledge review. - In: Cole, D., S. McCool, W. Borrie, J. O'Loughlin (Eds.). Wilderness Science in a Time of Change Conference - Vol. 5: Wilderness Ecosystems, Threats, and Management; 1999 May 23-27; Missoula, MT. Proceedings RMRS-P15-VOL-5. Ogden, UT: U.S. Depart. Agriculture, Forest Service, Rocky Mountain Research.

Marion, J., Y. F. Leung. 2001. Trail resource impacts and an examination of alternative assessment techniques. - J. Park Recreat. Adm., 19, 3, 17-37.

Marion, J., N. Olive. 2006. Assessing and understanding trail degradation: Results from big south fork National River and recreational area. - USDI, National Park Service, Final Research Report, 80 p.; https://doi.org/10.3133/5200309.

Marion, J., Y. F. Leung, H. Eagleston, K. Burroughs. 2016. A review and synthesis of recreation ecology. Research findings on visitor impacts to wilderness and protected natural areas. - J. For., 114, 3, 352-362; https://doi.org/10.5849/ jof.15-498.

Martin, R., D. Butler. 2017. A framework for understanding off-trail trampling impacts in mountain environments. The George Wright Forum, George Wright Society, 34, 3, 354-367.

Nedkov, S., A. Gikov, M. Nikolova, P. Dimitrov, E. Gachev. 2014. Mapping of ecosystem services in mountain areas: a case study of Seven Rila Lakes, Bulgaria. - In: Bandrova, T., M. Konechny (Eds.) Fifth Intern. Confer. Cartography and GIS, June 15-20, Riviera, Bulgaria, 488-497.

Nikolova, M., G. Zhelezov, S. Nedkov, P. Nozharov, Y. Krumova, V. Nikolov, A. Gikov, E. Gachev. 2012. Changes in the environment and current state of the protected area "Seven Rila Lakes". - Proc. 8th Sci. Confer. "SPACE, ECOLOGY, SAFETY”, 4-6 December 2012, Sofia (in Bulgarian).

Rangel, L., M. Jorge, A. Guerra, M. Fullen. 2019. Soil erosion and land degradation on trail systems in mountainous areas: Two case studies from South-East Brazil. - Soil Syst., 3, 3, 56; https://doi.org/10.3390/soilsystems3030056.

Salesa, D., A. Cerdà. 2020. Soil erosion on mountain trails as a consequence of recreational activities. A comprehensive review of the scientific literature. -J. Environ. Manage, 271, 110990; https://doi.org/10.1016/j.jenvman.2020.110990.

Sinnyovsky, D. 2014. The potential of Northern Rila as a geopark. - Ann. Univ. Mining and Geol., 57, 1-Geol., 13-18 (in Bulgarian with English abstract).

Sinnyovsky, D. 2015. Cvijch's investigations on the Quaternary glaciations in Rila as a basis for the development of geotopes of scientific and historical value. - In: Proc. $\mathrm{Na}$ tional Confer. Bulg. Geol. Soc. Geosciences 2015. Sofia, $157-158$ (in Bulgarian).

Tsvetkova, I., D. Sinnyovsky. 2015. Rock diversity and glacial forms in the area of the Seven Rila Lakes geotope. - Ann. Univ. Mining and Geol., 58, 1-Geol., 26-31 (in Bulgarian with English abstract).

Velchev, A., S. Tonkov, E. Bojilova. 2011. Paleogeomorphological and paleoecological development of Nordwestern Rila during the Pleistocene and Holocene. - Problems of Geography, 3-4, 35-49 (in Bulgarian with English abstract). 